\title{
Collapse of Tall Buildings in Multi-Storey Fires
}

\author{
DAVID LANGE and ASIF USMANI \\ BRE Centre for Fire Safety Engineering \\ Institute for infrastructure and the environment \\ School of Engineering and Electronics \\ The University of Edinburgh \\ Edinburgh \\ EH9 3JL
}

\section{ABSTRACT}

Developments in design methodologies and practices for structures in fire has for the last decade focussed on the horizontal stability of structures in fire. In this field there have been a number of developments of significance including the acceptance of membrane action as a viable load carrying mechanism under the large vertical displacements of floor systems which often occur during a fire. This research has focussed on two scenarios - simply supported floor systems and laterally restrained floor systems. Despite the large horizontal forces which the supporting structure must resist as a result of the adoption of these mechanisms in addition to the original vertical mechanical forces which were applied, very little research has been carried out into the consequences to the surrounding structure of the adoption of these mechanisms. These consequences were illustrated sharply by the collapse of the world trade centre twin towers on September the $11^{\text {th }} 2001$, where fires which raged inside of two tall steel structures ultimately brought about their collapse.

The analysis of tall structures in fire is often seen as the domain of large consultancies or groups with access to high performance computing facilities or expensive software packages. However, a simple analytical technique is derived here which allows for a quick assessment of the forces acting on a perimeter column given both single and multiple floor fires. Based on this analysis, a simple assessment methodology is proposed which allows for a quick design check of tall buildings exposed to multiple floor fires.

KEYWORDS: tall buildings, structural collapse, structural design, performance-based design

\section{NOMENCLATURE LISTING}

$\begin{array}{llll}A & \text { Area } & \text { Greek } & \\ E & \text { Modulus of elasticity } & \alpha & \text { Coefficient of thermal expansion } \\ F & \text { Tensile force } & \varepsilon & \text { Strain } \\ K & \text { Stiffness } & \Delta & \text { Increase in property } \\ L & \text { Length } & \sigma & \text { Stress } \\ N & \text { Pull-in force } & \text { subscripts } \\ T & \text { Temperature } & \text { max } & \text { Maximum total displacement } \\ u & \text { Horizontal displacement } & \mathrm{p} & \text { Mechanical effect } \\ V & \text { Shear force } & \mathrm{T} & \text { Thermal effect } \\ w & \text { Vertical displacement } & y & \text { Yield } \\ x & \text { Horizontal axis } & & \end{array}$

\section{INTRODUCTION}

Despite the events of September $11^{\text {th }} 2001$, there has been very little research carried out into the stability of tall buildings in multiple floor fires. Quiel and Garlock, [1,2], calculate the capacity of beam-columns based upon the axial elongation of the beam, using the column as a spring resisting this elongation; this, however, did not consider the beams acting as a catenary to support the static loading; and it did not consider collapse of the columns given fire on multiple floors. Analysis carried out at the University of Edinburgh on the world trade centre towers focused on identifying and understanding the mechanism which led to their collapse. Initial findings and a proposed collapse mechanism were presented in 2003, [3], with additional work presented in 2005, [4]. Further investigation into the collapse of tall buildings exposed to fire on multiple floors led to the postulation of a further collapse mechanism, [5]. The two collapse mechanisms are labelled, respectively, a strong floor, and a weak floor collapse mechanism, and 
although the method of collapse is different, the chain of events and structural behaviour leading to the mechanisms are much the same during the events leading to the resulting instabilities.

Although the scenario of multiple floor fires in tall-storey buildings is not one which needs to be considered in current design codes, the potential for such an event has been clearly demonstrated and the consequences of such an event are extremely high. In the following sections the two failure mechanisms are described and a simple analytical assessment of the mechanism leading to collapse is presented as well as a step by step methodology for the assessment of the stability of a frame.

\section{BACKGROUND}

\section{2-D Structural representation}

Although the following collapse mechanisms were initially identified for a very specific structure, the subsequent research which was carried out demonstrated their applicability to structures of a similar form, where external columns are connected to a stiff internal core by way of composite floor systems [5]. Such structures can be represented by some suitable 2-dimensional frame because of the repetition of the beam and column structure along the length of the building.

\section{Collapse mechanisms of tall buildings exposed to multiple floor fires}

The two collapse mechanisms identified in the numerical work carried out are termed a weak floor collapse mechanism and a strong floor collapse mechanism as shown in Fig. 1 below.

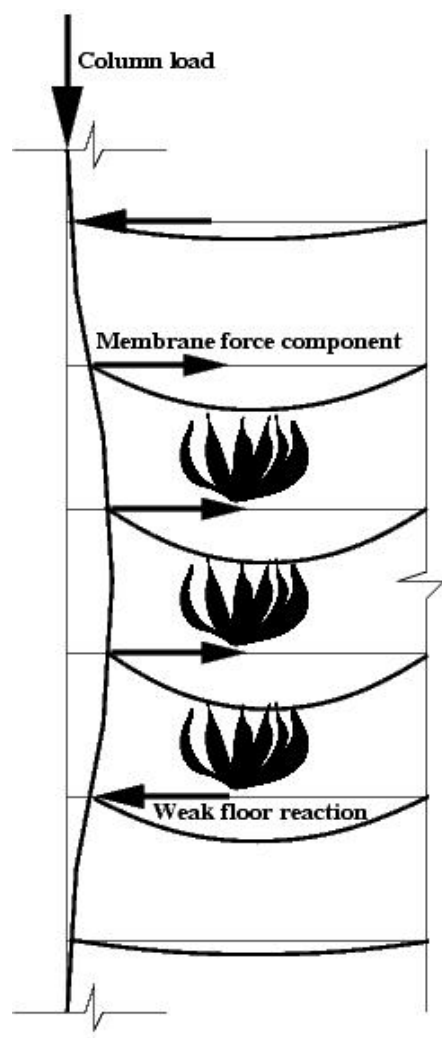

(a) Weak floors buckle

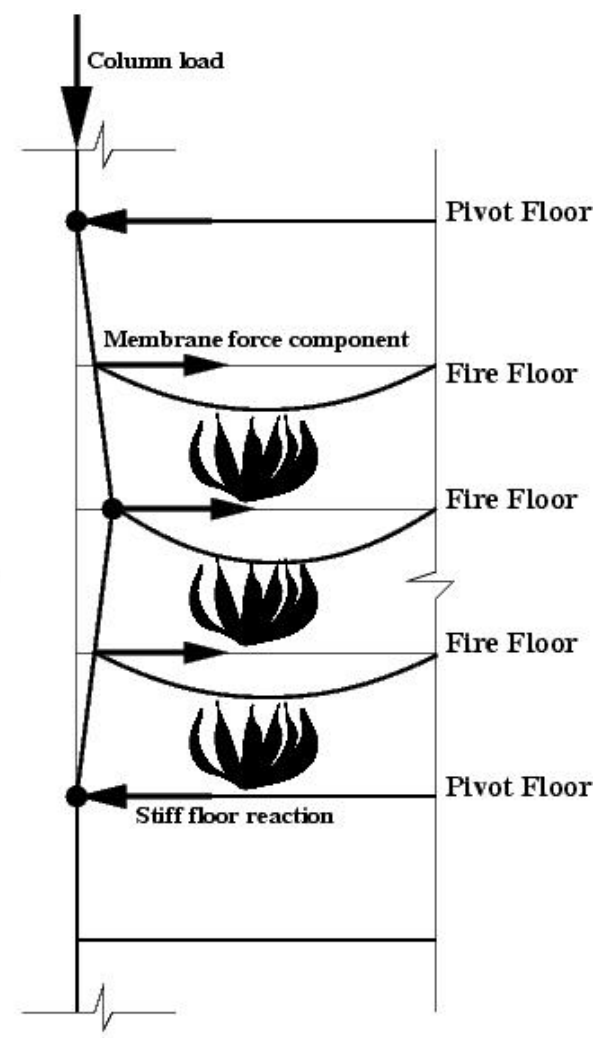

(b) Strong floors provide sufficient reaction

Fig. 1. Weak and Strong floor collapse mechanisms

\section{Weak floor collapse mechanism}

In the weak floor failure mechanism identified, illustrated in Fig. 1(a) for a 3 floor fire, fire acts on multiple floors. Initially, the floors are in a 'push-out' stage, where central deflection of the floor system is relatively low, and a flexural mechanism is still active. With increasing thermal deflection of the fire floors, 
caused by a combination of thermal expansion and thermal bowing, the push-out stage is followed by a 'pull-in' stage and the fire floors begin to experience increasing tensile catenary forces which must be resisted by the reaction forces from adjacent pivot floors not affected by fire. Where the pivot floor is unable to sustain the increasing reaction it buckles and the force is then transferred to next adjacent floor. Progressive collapse ensues as the buckling 'wave' is propagated along the length of the column.

\section{Strong floor collapse mechanism}

In the strong floor failure mechanism, illustrated in Fig. 1(b) for a 3 floor fire, initial response is similar to that of the weak floor failure mechanism. At the point where all fire floors adopt a catenary rather than a flexural mechanism, the stronger pivot floors are able to resist the induced axial load. In this instance, the pull-in forces exerted on the column by the fire floors acting as membranes causes the formation of 3 plastic hinges (column reaches full plastic yield through a combination of axial compression and bending), thus initiating collapse. This collapse is initiated by localised hinge formation, which is not as inherently progressive as the weak floor mechanism, however once the three hinges are formed then the loads from the superstructure will perpetuate the collapse.

\section{THERMAL RESPONSE OF FLOOR SYSTEMS}

The behaviour of a floor system under large displacements has been a topic of research for some time. The initiation of large central displacements in a floor system leads to a compressive membrane action developing in a slab as the edges attempt to rotate through a fixed support causing compressive stresses to build up in the membrane of the floor system. An increase in the deflection of the slab causes a transition from the compressive membrane mechanism to a tensile membrane mechanism. However, the tensile membrane mechanism at ambient generally provides no benefit over the compressive membrane mechanism and is often of lower capacity, therefore much of the research into the utilisation of membrane mechanisms at ambient temperatures was focussed on the benefits of a compressive membrane[6,7].

Following the Cardington tests in the late 1990's, the mobilisation of a tensile membrane or a catenary action in floor systems as an alternative mechanism for carrying load was seen to be a realistic one[8]. This was due to the increased temperature inducing large thermal strains which allowed the floor system to adopt larger total deflections without a corresponding increase in stress. A number of methodologies have been derived which take advantage of a tensile membrane mechanism in fire[9-12].

Because any exposed steel plate on the underside of a composite deck is exposed to high temperatures in fire and is therefore of reduced stiffness and strength any resistance is assumed to come from the steel reinforcement which is embedded in the floor system. The thermal deflection of the steel is governed by the thermal deflection of the concrete decking of the floor system. This thermal deflection has two components, one caused by the average temperature increase and one by the temperature gradient in the concrete as a result of heating on one surface.

Given some compartment fire underneath the floor slab, the non-linear temperature distribution in the concrete floor system is idealised by a uniform temperature increase, $\Delta T$, and an equivalent thermal gradient, $T_{, z}[13]$.

The average temperature in the beam leads to the development of some uniform thermal strain, $\varepsilon_{T}$, in the floor [14]. The effect of the thermal strain in the concrete section is an expansive 'push-out' against the supports. Where the beam is simply supported, this causes an elongation in the floor system - a thermal expansion without the development of a thermal stress. If the beam is restrained against translation the increase in temperature causes a build up in compressive stress in the beam as it tries to push out against the support.

The equivalent thermal gradient in the beam causes some curvature strain, $\varepsilon_{\Phi}$, to develop in the section: the cold upper area of the section develops some tensile strain due to compatibility with the hot lower area of the section which is subject to compressive strain as a result of the restraint of the cooler area. This does not lead to a change in the overall length of the floor system, however where the floor is simply supported the distance between the supports changes as a result of the curvature of the system. If the floor is restrained against axial translation at the supports then tensile forces develop in the section as a result of the curvature strains. 
The combined effect of thermal expansion and curvature strains lead to some thermal displacement occurring within the floor system and some membrane force at the support.

\section{DETERMINATION OF THE PULL-IN FORCES}

Where the steel reinforcement of the floor system experiences some average temperature increase, $\Delta \mathrm{T}$, the thermal length of the steel is given by Eq. 1:

$$
L_{T}=L(1+\alpha \Delta T)
$$

It is assumed that the floor system is supported between an internal core or stiff structure and the external column. As the central deflection of the floor system develops, the concrete decking experiences widespread tensile cracking and the tension-compression couple that provides flexural resistance to the imposed loading, $p$, is withdrawn, allowing a catenary mechanism to develop to sustain the imposed load. Under the catenary mechanism, the steel in the floor is subjected to tensile forces which have some horizontal and a vertical component at the supports. The horizontal component of this force, $N_{p}$, causes some deflection, $u_{p}$, in the external column, Fig.2, which is restrained by the horizontal stiffness, $K_{T}$, of the entire exterior column. This stiffness can be calculated for a given number of fire floors using the stiffness method, by determining the horizontal force required to apply unit displacement to the horizontal degrees of freedom one by one, Fig. 3. The pivot floors above and below the fire floors provide some rotational restraint of the column, $\mathrm{K}_{\mathrm{RP}}$.

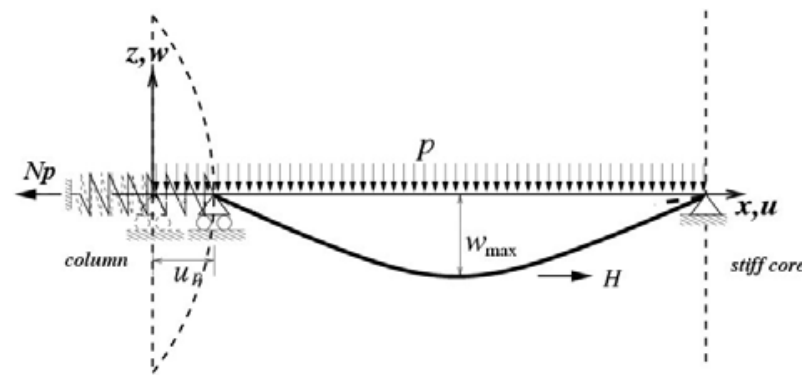

Fig. 2. The horizontal force causes some lateral deflection of the column at the connection which is restrained partially by the stiffness of the column.

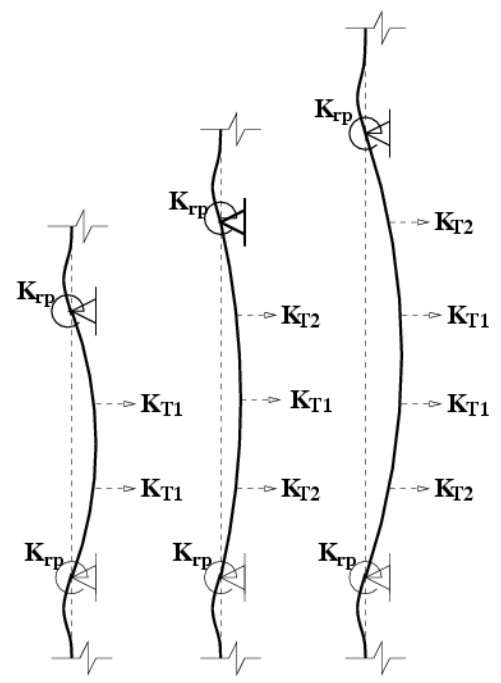

Fig. 3. Horizontal stiffness of the column given fire on increasing number of floors

The horizontal pull-in force is related to the lateral deflection of the column by the stiffness, Eq. 2 : 
Considering the forces acting on the steel reinforcement at the deflection required to sustain the imposed load, Fig. 4, the tensile force in the reinforcement at a position $\mathrm{x}$ along the floor system, $F(x)$, is given by Eq. 3:

$F(x)=\sqrt{N_{p}(x)^{2}+V(x)^{2}}$

This tensile force is used to determine the strain in the steel at any distance along the floor, Eq. 4. By integrating the strain across one half of the length of the floor system, the increase in length of the floor system under static loading can be calculated, Eq. 5 .

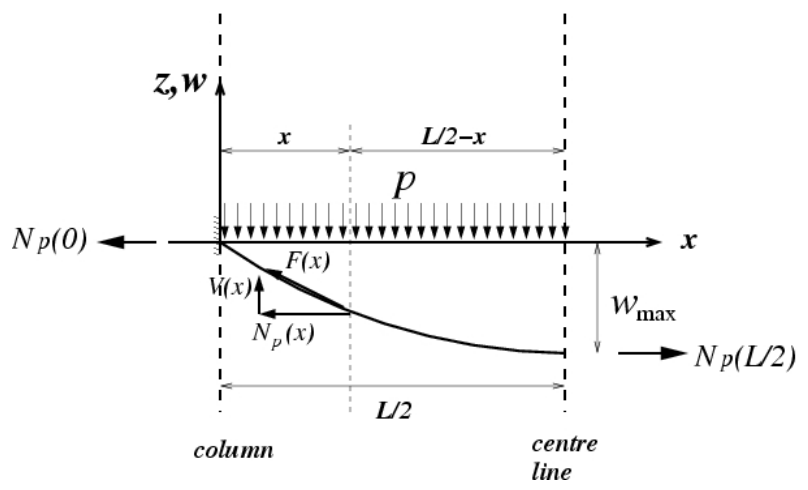

Fig. 4. Forces acting on the floor system at the deflection required to sustain the imposed load

$\varepsilon_{s}(x)=\frac{A_{s} E_{s}(T)}{F(x)}$

$\Delta L_{p}=2 \int_{0}^{L / 2} \varepsilon_{s}(x) d x$

Assuming that the deflected shape of the floor under the combined static and thermal loading is that of a sine curve, the horizontal reaction can also be approximated by:

$N_{p}=\frac{p L^{2}}{2 \pi w_{\max }}$

Assuming that the change in distance between the supports is minimal, i.e. $\varepsilon_{\Phi} \approx \varepsilon_{\mathrm{T}}$, the maximum vertical displacement of the floor system can by approximated by the following relationship with the thermal length of the floor system and the increase in length under static loading:

$w_{\max }=\frac{2 L}{\pi} \sqrt{\frac{L_{T}+\Delta L_{p}}{L}}$

Equations (2), (5), (6), and (7) can be solved simultaneously for the four unknowns $w_{\max }, u_{p}, \Delta L_{p}$, and $N_{p}$. 


\section{DESIGN METHODOLOGY}

The steps in the analysis are as follows:

Step 1. Structure and Thermal Loading

Based on appropriate risk based criteria, establish the following:

a. An adequate two-dimensional representation of the structural frame, including the exterior columns and the adjacent structural framing, which is assumed to be restrained in the interior by a stiff core;

b. The time dependent magnitude of fire in the compartments adjacent to the exterior columns of the structure (using one of BS476, ISO834, ASTME119 or Eurocode 1 based curves or other more advanced fire models);

c. The number of floors involved in the fire;

d. The temperature distribution in the structural members of the frame (columns and floor systems) at the end of the heating curve using appropriate code formulas or tables or heat transfer calculations;

e. Convert the temperature distribution at the end of the heating phase to an equivalent uniform temperature and through depth thermal gradientt.

Step 2. Floor Mechanical Loading

Determine the mechanical state of the floor system after application of the design thermal input (i.e the reduction in strength and stiffness of the component materials and the change in geometry) ignoring the mechanical loading, and follow these steps:

a. Check if the applied uniformly distributed load (using appropriate reduction factors allowed by code) on the floor can be resisted through residual flexural capacity - if this is the case, stop the analysis as the structure can not fail in either of the two collapse mechanisms identified;

b. If the design udl is greater than the flexural resistance of the floor, check to see if the udl can be resisted by the floor system through catenary action, here the concrete tensile resistance is ignored and only the reinforcement and any composite structural steel are assumed to provide catenary resistance. If the floor system is unable to provide the tensile resistance (limited by rupture of reinforcement and fracture of structural steel connection) than the floor system fails, leading potentially to progressive collapse. The floor system should be redesigned until it is able to resist the udl through flexure or catenary action.

c. Determine the "pull-in" forces applied on the column by the fire floors sagging in catenary action.

Step 3. Column Mechanical Loading

Using the catenary "pull-in" forces applied by the floors, obtain the moments induced in the columns at the "pivot" floors (adjacent to the fire floors) and in the centre of the height between the pivot floors. Use an approximation of the column internal displacement to calculate the additional $\mathrm{P}-\delta$ moments experienced by the columns.

Step 4. Check for Weak Floor Collapse Mechanism

Calculate the reaction of the pivot floors counteracting the membrane "pull-in" forces. If the floor membrane is unable to provide the reaction calculated, a weak floor failure becomes possible. This failure is relatively less likely to occur as it requires the pull in forces from many floors on fire. However a combination of the membrane compression induced in the floor and the additional moment imposed on the 
sagging floor by the P- $\delta$ effect and by the rotation of the column may also cause a combined bending and compression failure of the floor with only a few floors on fire, also leading to a weak floor failure.

\section{Step 5. Check for Strong Floor Collapse Mechanism}

Perform a 2nd order analysis to calculate the column deflection under the "pull-in forces" from the fire floors. Check the temperature dependent moment-force interaction diagram for the column to ensure that the column has not reached yield surface (and thus formed a plastic hinge). If this is the case at all three locations (pivot floors and middle fire floor) then the strong floor failure mechanism identified can occur as the three hinges form a mechanism.

\section{EXAMPLE 1}

To illustrate the methodology in use, the following structure is checked for either of the two collapse mechanisms presented:

- a 12 storey frame, consisting of a $305 \times 305 \times 137$ UC section, braced to a stiff internal core by a series of composite concrete floors at spacing of $4 \mathrm{~m}$;

- floor systems span $8 \mathrm{~m}$, have a width of $6 \mathrm{~m}$, and concrete depth $100 \mathrm{~mm}$ with an $A_{s}$ of $142 \mathrm{~mm}^{2} / \mathrm{m}$ positioned mid way through the slabs depth, $\sigma_{\mathrm{y}}$ of the steel reinforcement is $600 \mathrm{MPa}$;

- Total uniform distributed loading on the floor system is $7.5 \mathrm{kN} / \mathrm{m}^{2}$.

Step 1. Structure and Thermal Loading

The structure is represented by a 2-dimensional frame, similar to that shown in Fig. 1. Line loading on the floor representing the entire UDL is $45 \mathrm{kN} / \mathrm{m}$ length of floor. Thermal loading is approximated by an average temperature increase of $150^{\circ} \mathrm{C}$ and an equivalent thermal gradient of $5^{\circ} \mathrm{C} / \mathrm{mm}$.

Lateral stiffness to translation at the floor levels is calculated taking into account the contribution to the stiffness of the floors immediately above and below the pivot floors.

\section{Step 2. Floor Mechanical Loading}

The severe thermal gradient which is imposed on the floor slab will cause large thermal displacements, and therefore it can be assumed that flexural capacity is not available as a viable load carrying mechanism under the prescribed conditions.

Following the method presented, the unknowns from equations (2), (5), (6) and (7) from the floor acting on the column are as follows, for one mid-height floor on fire:

Table 1. Pull-in forces

\begin{tabular}{|l|c|r|r|}
\hline Pull-in forceH $(\mathbf{N})$ & $\begin{array}{c}\text { Vertical deflection } \\
\mathbf{w}_{\max }(\mathbf{m m})\end{array}$ & $\begin{array}{c}\text { Lateral deflection } \\
\mathbf{u}_{\mathbf{p}}(\mathbf{m m})\end{array}$ & $\mathbf{\Delta L}_{\mathbf{L}} \mathbf{( m m )}$ \\
\hline $4.6 \times 10^{5}$ & 785 & 36.0 & 98.9 \\
\hline
\end{tabular}

The increase in length of the floor system is $98.8 \mathrm{~mm}$, equating to an average strain in the reinforcement of $1.2 \%$, which is less than the rupture strain for standard ductility reinforcement steel as described in EC2 [15]. The pull-in force equates to an average stress of 540MPa on the steel reinforcement, which is less than the yield stress stated.

Step 3. Column Mechanical Loading

Assuming that there are 3 fire floors, above which are 6 non-fire floors the axial load on the column at the level of the top pivot-floor is $2160 \mathrm{kN}$. Performing a $2^{\text {nd }}$ order elastic analysis on the structure using the program Mastan 2[16], the maximum moment on the column as a result of the combined P- $\delta$ moment and the pull-in forces is $1.6 \times 10^{6} \mathrm{Nm}$. The horizontal reaction forces at the pivot floors is $1.4 \times 10^{6} \mathrm{~N}$.

Step 4. Check for Weak Floor Collapse Mechanism

The steel beam acting in composite with the floor system should be able to withstand an axial load of $1.4 \mathrm{x}$ $10^{6} \mathrm{~N}$ without buckling. The capacity of the floor system to withstand the axial load can be enhanced by 
considering the combined buckling capacity of the steel beam and concrete decking acting in composite, using an appropriate modular ratio.

\section{Step 5. Check for Strong Floor Collapse Mechanism}

The column section obviously has some effect on the stiffness to lateral translation, and therefore will have a small effect on the pull-in forces calculated in the analysis. However, the column design should be iterated to withstand the maximum moment as calculated.

\section{A VERY SIMPLE VERSION OF THE METHOD USED TO ASSESS WTC TOWER COLLAPSES}

Flint et. al. 2007 [5] have published the results of their computational analysis of 2D models of the WTC towers (as shown in Fig. 5). This analysis shows a strong floor type collapse mechanism with hinges developing in columns. A highly practical and simplified version of the method is presented here to check whether the failure predicted by the finite element model can be reproduced here

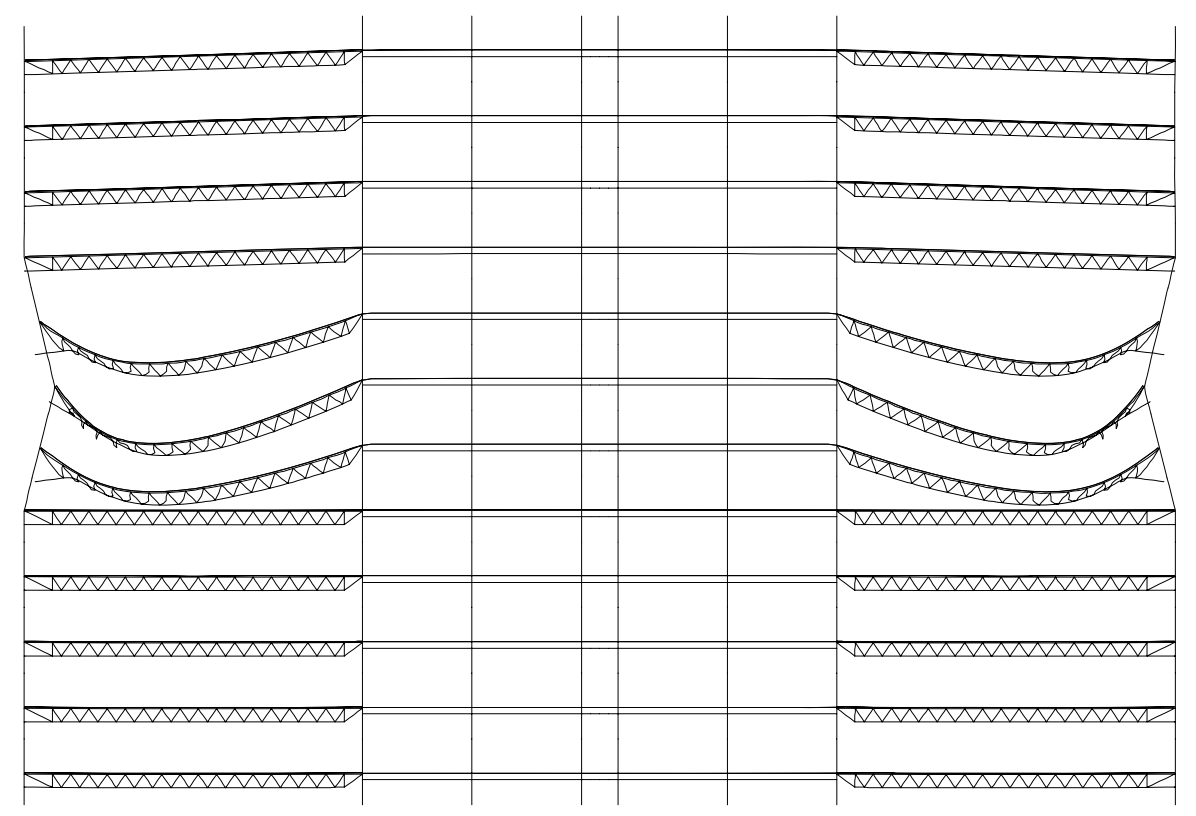

Fig. 5. Strong floor localised collapse that will initiate progressive collapse (2D WTC Model)

This analysis uses the simple formulas provided in [14] to calculate the thermally induced deflections in the 18 meter span of the truss-supported WTC floor system based on the temperature distributions shown in Fig. 8. As discussed in [3], when exposed to fire the slab first pushes the column out and then as the thermal gradient effect become dominant and the structural steel loses its strength and stiffness the floor membrane begins to hang in tension anchored to the core on one side and supported by the perimeter column wall on the other. The horizontal component of the tensile force in the slab $(\mathrm{H})$ begins to pull the column wall in. The force increases as the flexure capacity reduces and reaches a peak value at some value of the floor deflection at midspan, beyond this point any further deflections reduce the tensile force. The gravity load on the floor system contributes to the deflection, but the predominant portion of this is caused by the thermal gradient. From Fig. 6 this can be estimated to be approximately $5^{\circ} \mathrm{C} / \mathrm{mm}$. Over an 18 meter span this translates to a deflection of about $2500 \mathrm{~mm}$. However, this deflection accompanies a reduction in span of about $800 \mathrm{~mm}$ (assuming a $350^{\circ} \mathrm{C}$ average temperature increase, corresponding to a 90 minute fire). The reduction in span will naturally be resisted by the column wall. The formulas for calculating this exactly (and hence the correct floor deflection) in the first part of this paper. From a number of analyses a thumb rule of $\operatorname{span}(\mathrm{L}) / 10$ can be used to for the floor midspan deflection, i.e. $1800 \mathrm{~mm}$, which we refer to as $\delta$. 


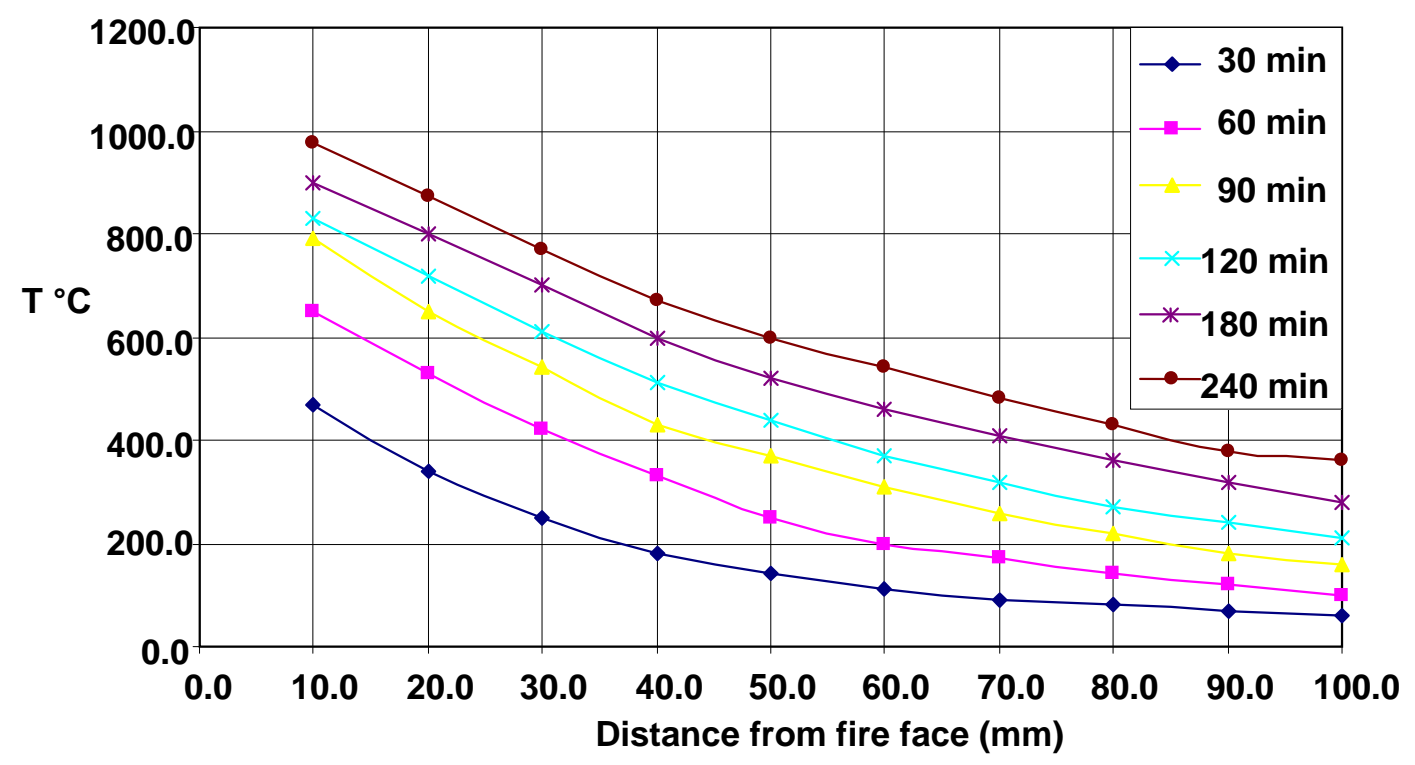

Fig. 6. Temperature evolution in composite slab

The udl on the floor is assumed to be $3 \mathrm{kN} / \mathrm{m}^{2}$. The column section as modelled is shown in Fig. 7. This was necessary as the columns were 1 meter apart and the trusses are two meter apart in the structure. Therefore the udl applied to the member representing the floor was $6 \mathrm{kN} / \mathrm{m}$.

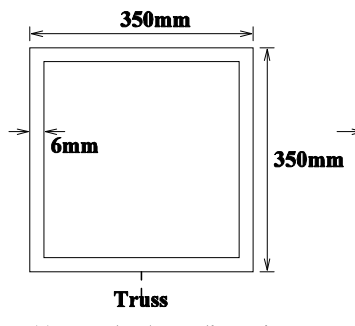

(a) Actual column dimensions

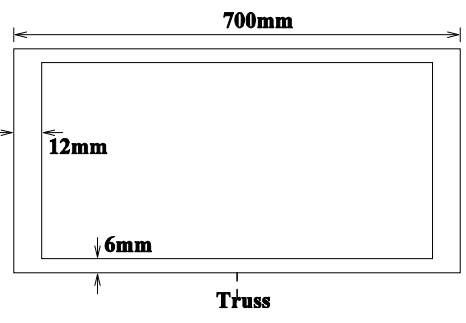

(b) A pair of columns as modelled

Fig. 7. Columns as modelled

Equating the moment $\mathrm{wL}^{2} / 8$ to $\mathrm{H} \delta$ the value of $\mathrm{H}$ can now be calculated to be $1.25 \mathrm{wL}$ or numerically $135 \mathrm{kN}$. Now the stability of the perimeter column can be assessed for a three floor fire as discussed below. Figure 8 shows a simple model of the column, reduced by using symmetry at the point of the middle hinge and truncated at the floor below the lower pivot floor. The symmetry point is assumed to be the $97^{\text {th }}$ floor (WTC tower 1) with 13 floors above that point imposing an estimated load of $700 \mathrm{kN}$ at that point. 


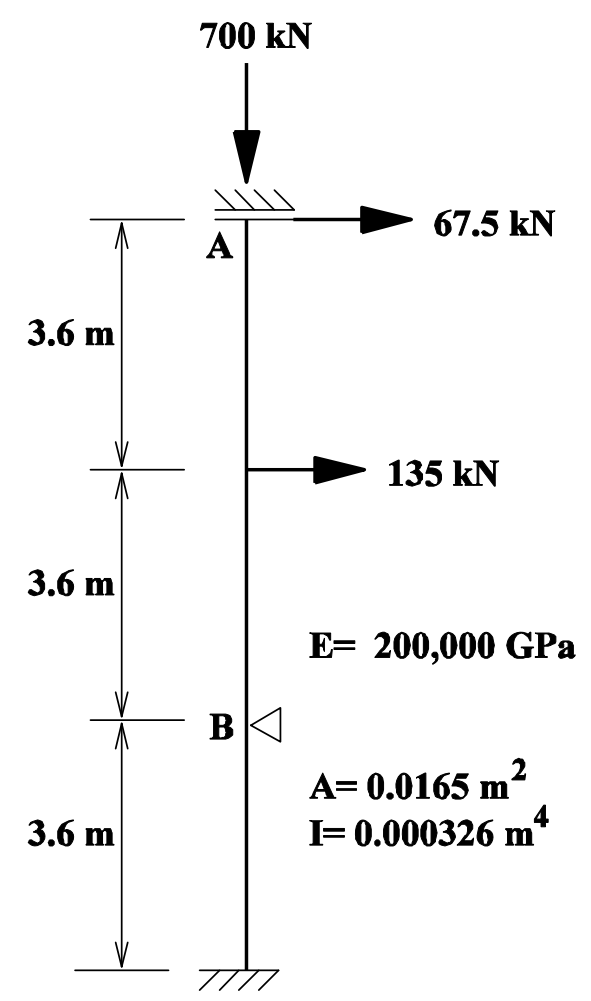

Fig. 8. Simple analysis model

The model of Fig. 8 requires a $2^{\text {nd }}$ order analysis because of the interaction between the axial (representing the load of the superstructure) and lateral loading (representing the tensile pull-in forces from the floor system). This was carried out to obtain results as follows:

1. Lateral displacement at $\mathrm{A}=97 \mathrm{~mm}$

2. Moment at $\mathrm{A}=462.6 \mathrm{kNm}$

3. Moment at $\mathrm{B}=570.4 \mathrm{kNm}$

Assuming the yield stress of the column to be $300 \mathrm{MPa}$ (the WTC steel ranges from 250 to $690 \mathrm{MPa}$ ) the full plastic moment capacity (Mp) of the column section is $639 \mathrm{kNm}$ and its compressive strength $(\mathrm{Pp})$ is $4954 \mathrm{kN}$. The linear column interaction formula $(\mathrm{M} / \mathrm{Mp}+\mathrm{P} / \mathrm{Pp}<1.0)$ can be used to conservatively estimate whether the column capacity will be sufficient for this, where $\mathrm{M}$ is $570.4 \mathrm{kNm}$ and $\mathrm{P}$ is $700 \mathrm{kN}$. This gives a value of 1.03 which is marginally greater than 1.0 however it does clearly suggest that a hinge is very likely to be formed at point $\mathrm{B}$, which will inexorably lead to a hinge at A because of the P- $\delta$ effect, leading to strong floor collapse as discussed earlier. Although the steel yield stress used in this analysis to be on the low side (assuming that the steel on the top level will perhaps be lower strength due to reduced loading), no further reduction is assumed because of the effect of fire and the full ambient value is used. This is not an unreasonable assumption as the perimeter columns have three sides exposed to the atmosphere, however some temperature increase will be expected as fires burn hottest near perimeter openings, i.e. adjacent to the columns.

\section{CONCLUSIONS}

The collapse of tall buildings in densely populated urban setting is a scenario too terrible to contemplate. Buildings are routinely designed to resist this limit state under the extreme load conditions of high winds and earthquakes etc. however the potential of multiple floor fires to cause such a disaster remains unrecognised in the profession as no current building codes require the consideration of this type of extreme loading. It is clearly demonstrated in this paper that collapse of tall buildings in multiple floor 
fires is a distinct possibility as the mechanisms that can cause this are easily reproduced using a non-linear finite element analysis programme.

The events of September 11, 2001 saw three very tall buildings collapse within hours of each other primarily because of fire. The simple analysis carried out here further confirms the computational models used to investigate these events and points to a significant vulnerability in the design of the WTC structure for large fires, albeit no regulations required this, and still don't, which in the light of recent research such as this seems unfortunate.

This paper clearly shows that the assessment of the collapse potential of a frame in multiple floor fires need not always require rigorous, labour intensive and time consuming finite element analyses. It is possible for frames of relatively regular geometry to be assessed using these simple, cost effective and quick methods.

\section{REFERENCES}

[1] Quiel, S.E., and Garlock, M.E.M., A performance-based design approach for steel perimeter columns subject to fire, in Fourth International Workshop Structures in Fire. 2006: Aveiro.

[2] Garlock, M.E.M., and Quiel, S.E., Combined axial load and moment capacity of fire-exposed beam-columns with thermal gradients, in Fourth International Workshop Structures in Fire. 2006: Aveiro.

[3] Usmani, A.S., Chung, Y.C., and, Torero, J.L., How did the WTC Towers Collapse? A New Theory. Fire Safety Journal, 2003. 2003(38): p. 501-533. doi:10.1016/S0379-7112(03)00069-9

[4] Usmani, A.S., Stability of the World Trade Center Twin Towers Structural Frame in Multiple Floor Fires. Journal of Engineering Mechanics, 2005. 131(2005): p. 654-657. doi:10.1061/(ASCE)0733-9399(2005)131:6(654)

[5] Flint, G.R. et. al., Structural Response of Tall Buildings to Multiple Floor Fires, Journal of Structural Engineering, ASCE, 2007, 133(12), p. 1719-1732 doi:10.1061/(ASCE)07339445(2007)133:12(1719).

[6] Salami, A.T., Equation for predicting the strength of fully-clamped two-way reinforced concrete slabs. Procedures of the Institution of Civil Engineers Structures and Buildings, 1994. 1994(104): p. 101-107.

[7] Black, M.S.,Ultimate Strength Study of Two-Way Concrete Slabs. Journal of the Structural Division, ASCE, 1975. January 1975: p. 311-324.

[8] Behaviour of steel framed structures under fire conditions, Main report, DETR PiT project. 2000.

[9] Bailey, C.G., and Moore, D.B., The structural behaviour of steel frames with composite floor slabs sunject to fire: Part 1: Theory. The Structural Engineer, 2000. 78/11(2000): p. 19-27.

[10] Bailey, C.G., and Moore, D.B., The structural behaviour of steel frames with composite slabs subject to fire: Part 2: Design. The Structural Engineer, 2000. 78/11(2000): p. 28-33.

[11] Cameron, N.J.K., and Usmani, A.S., A new design method to determine the membrane capacity of laterally restrained composite floor slabs in fire Part 1: Theory and method. The Structural Engineer, 2005. 83(19): p. 28-33.

[12] Cameron, N.J.K., and Usmani, A.S., A new design method to determine the membrane capacity of laterally restrained composite floor slabs in fire part 2: Validation. The Structural Engineer, 2005. 83(19): p. 34-39.

[13] Gillie, M., Usmani, A., Rotter, M., and O'Connor, M., Modelling of heated composite floor slabs with reference to the Cardington experiments. Fire Safety Journal. 2001(36): p. 745-767. doi:10.1016/S0379-7112(01)00038-8

[14] Usmani, A.S., J.M. Rotter, S. Lamont, A.M. Sanad and M. Gillie, Fundamental principles of structural behaviour under thermal effects. Fire Safety Journal. 2001(36): p. 721-744.

doi:10.1016/S0379-7112(01)00037-6 
[15] EN 1992-1-2:2002 Eurocode 2: Design of concrete structures - Part 1-2: Structural fire design.

[16] Ziemian, R.D., and McGuire, W., Mastan 2. 2000. 